\title{
Choice of unmanned aerial vehicles for identification of mosquito breeding sites
}

\author{
Franciely Velozo Aragão, ${ }^{1}$ Fernanda Cavicchioli Zola, ${ }^{1}$ Luis Henrique Nogueira Marinho, ${ }^{2}$ \\ Daiane Maria de Genaro Chiroli, ${ }^{1}$ Aldo Braghini Junior, ${ }^{1}$ João Carlos Colmenero ${ }^{1}$ \\ ${ }^{1}$ Department of Industrial Engineering, Federal University of Technology (UTFPR), Paraná; ${ }^{2}$ Department \\ of Exact Sciences, Universidade Estadual de Londrina (UEL), Brazil
}

\begin{abstract}
The disordered urban growth that may favour the emergence of the Aedes aegypti mosquito in cities is a problem of increasing magnitude in middle- and high-income countries in the tropical part of the world. Currently, the World Health Organization (WHO) considers the control and elimination of Ae. aegypti a world-wide high priority as it is the main vector of many rapidly spreading viral diseases, dengue in particular. A major difficulty in controlling the proliferation of this vector is associated with identification of the breeding sites. The use of Unmanned Aerial Vehicles (UAVs) can be an efficient alternative to manual search because of high mobility and the ability to overcome physical obstacles, particularly in urban areas where it can offer close-up images of potential breeding sites that are difficult to reach. The objective of this study was to find a way to select the most suitable UAV for the identification of Ae. aegypti habitats by providing images of potential mosquito breeding sites. This can be accomplished by a Multiple-Criteria Decision Method (MCDM) based on an Analytical Hierarchy Process (AHP) for the evaluation of weights of the criteria used for characterizing UAVs. The alternatives were analyzed and ranked using the Fuzzy Set Theory (FST) merged with the Technique for Order of Preference by Similarity to Ideal Solution (TOPSIS). The methodology is explained and
\end{abstract}

Correspondence: Franciely Velozo Aragão, Federal University of Technology, (UTFPR). Av. Monteiro Lobato, Km 04, 84016-210 Ponta Grossa, Paraná, Brazil.

E-mail: fran-aragao@hotmail.com

Key words: Aedes Aegypti; Unmanned Aerial Vehicle; MCDM; Fuzzy Set Theory; Fuzzy TOPSIS, Brazil.

Funding: This study was supported in part by the Coordenação de Aperfeiçoamento de Pessoal de Nível Superior (CAPES), Brazil.

Conflict of Interests: The Authors declare no potential conflict

Received for publication: 27 August 2019.

Accepted for publication: 12 April 2020.

(C) Copyright: the Author(s), 2020

Licensee PAGEPress, Italy

Geospatial Health 2020; 15:810

doi:10.4081/gh.2020.810

This article is distributed under the terms of the Creative Commons Attribution Noncommercial License (CC BY-NC 4.0) which permits any noncommercial use, distribution, and reproduction in any medium, provided the original author(s) and source are credited. discussed with respect to identification and selection of the most appropriate UAV for aerial mapping of Aedes breeding sites.

\section{Introduction}

The proliferation of the mosquito Aedes (Stegomyia) aegypti is a major public health problem, mainly because of its potential as the vector of dengue (Espinosa et al., 2016). This disease is considered the fastest growing endemic disease of the 21st century by the World Health Organization (WHO), which estimates that 390 million people worldwide are infected with this virus (Bhatt et al., 2013; Liu-Helmersson et al., 2019, WHO, 2020). Southeast Asia and the Western Pacific are currently reporting the highest incidence of the disease, while Latin America also has seen the number of dengue cases increase considerably in recent years (WHO, 2017; Ferreira et al. 2018). However, Ae. aegypti is not only the main vector of dengue but also of other arboviruses of growing importance, such as chikungunya dengue, yellow fever and zika (Khormi and Kumar, 2012; Brown et al., 2014; Gloria $\square$ Soria et al., 2016). The threat is increasing due to the current signs of climate change which favour the basic conditions of Ae. aegypti breeding sites. This association is further strengthened by the mosquito's potential for dispersion and ability to adapt to new environments, and the deficiency in basic sanitation installations for humans. Taken together, these facts indicate that the environmental conditions in the tropical areas of the world are gradually becoming more suitable for mosquito proliferation (Khormi and Kumar, 2014; Donalisio et al., 2017; Sarfraz et al., 2014; Liu et al., 2019). Indeed, large epidemics caused by arboviruses have been recorded in the last few years (Madariaga et al., 2016; Carvalho et al., 2017; Maitra et al., 2019). Thus, control and elimination of Ae. aegypti, constitute a looming problem calling for immediate implementation of effective entomological surveillance combined with development of new vector control measures. The authorities responsible for urban health attempt to identify mosquito breeding sites, spray insecticides and raise awareness of the epidemiological scenario caused by the Ae. aegypti vector (Chiroli et al., 2017). The use of Unmanned Aerial Vehicles (UAVs), a technology that can aid the work of public health officers, has been used to identify possible mosquito breeding sites that are otherwise difficult to reach. Because they can be manoeuvred to overcome physical obstacles that prevent human access, UAVs are effective alternatives to manual exploration. Applied as a platform for imagery, mapping and data collection by remote control, The UAV can assist various types of studies, such as precision agriculture, urban mapping, study of risky areas and control of endemic vectors (Machault et al., 2011; Hay et al., 2013; Turner et al., 2015).

Studies to identify Ae. aegypti breeding sites by means of 
UAVs have been promoted, e.g., by Amarasinghe et al. (2017), while UAVs can also be used for insecticide spraying (Amenyo et al., 2014). In Brazil, the International Atomic Energy Agency (IAEA) is planning to use the Sterile Insect Technique (SIT) to assist controlling this vector by the release of sterile male mosquitoes to counteract the production of offspring leading to a reduction of mosquito populations (IAEA, 2018). This approach is still in the experimental phase but the first sterile mosquito release test, for which they used UAVs, has recently been completed.

Considering that UAVs come in different sizes and with various specifications, numerous criteria need to be considered to identify the solution that best suits the search for Ae. aegypti breeding habitats. Different decision-support approaches, such as MultipleCriteria Decision Methods (MCDM), can assist decision-makers in solving problems where several objectives need to be satisfied simultaneously. Two MCDMs, focused on standardizing the decision-making process through mathematical modelling, have been used to solve the issue at hand: the Analytical Hierarchy Process (AHP) that allows the hierarchization of the set of decisions to apply (Forman and Gass, 2001; Mahdi and Alreshaid, 2005), and the approach called Technique for Order of Preference by Similarity to Ideal Solution (TOPSIS), originally developed by Hwang and Yoon (1981) and later updated by Yoon (1987) and Hwang et al. (1993). Another methodology of interest in this context is the Fuzzy Set Theory (FST). While classical set theory has binary outcomes, i.e. either an element belongs to a specific set or it does not, FST permits gradual assessment of membership. For example, some sets are clearly delineated, e.g., the set of 'all people' or the set of 'all men', while others, e.g., 'all beautiful people', are less well defined. Thinking about this, Zadeh (1965) came to the conclusion that such imprecisely defined sets play a role in information technology and abstract mental activities, such as pattern recognition and recognisance. For such classes of elements, he introduced the concept 'fuzzy sets' and showed that their numbers are larger than those of the ordinary binary sets and have a wide scope of applicability in real life as they can be used in domains for which information is incomplete or imprecise.

The first hybrid concept involving both TOPSIS and FST was offered by Chen (2000) as a tool for decision-making in uncertainty scenery. This 'Fuzzy TOPSIS' approach was used by Tzeng and Huang (2011) as a way to select the best of multiple alternatives in problems with a finite number of criteria. Of importance for this study is that the Fuzzy TOPSIS method can evaluate UAV ranking by recognizing that the optimal one is the alternative nearest to the Fuzzy Positive Ideal Solution (FPIS) and farthest from the Fuzzy Negative Ideal Solution (FNIS). To identify the best score, the methodology handles the uncertainty in comparing a set of alternatives by selecting weights for each criterion. We chose AHP over an assortment of MCDMs to decide the values of these weights since this strategy permits the decision-maker to analyse, in a pairwise way, which criteria are the most critical based on the reality experienced in each case. It should be emphasised that Fuzzy TOPSIS also allows trade-offs between criteria, where a poor result in one criterion can be negated by a good result in another, an approach which is more realistic than non-compensatory methods that include or exclude alternative solutions based on non-negotiable cut-off decisions. Although none of the methods developed for decision-making are new, their combination for choosing an UAV for the identification of Ae. aegypti breeding sites represents a novel approach. This study proposes a hybrid methodology to rank criteria and alternatives at the different levels that must be considered when selecting the best possible craft for this kind of investigation.

\section{Materials and Methods}

\section{Study area and dispositions}

The study site was Maringá, which is situated in a region of high climatological risk for the infestation of Ae. aegypti in the Northwest of the Brazilian State Paraná. The latest available census data from the Instituto Brasileiro de Geografia Estatística (IBGE) are from 2010 and give an estimated population of $357,117,000$ inhabitants with a population density of 733.14 per $\mathrm{km}^{2}$ (IBGE, 2010). The territorial area of Maringá amounts to $487.5 \mathrm{~km}^{2}, 83 \%$ of which is currently connected to a sewage system, (IBGE, 2010). Maringá has a health development index (HDI) of 0,808 .

Brazil uses a Fast Index Survey (LIRAa) to estimate the level of Ae. aegypti infestation in the municipalities. According to the LIRAa for 2019, the Maringá region presents a general index of $4.2 \%$, which is considered a high risk, characterizing one of the four municipalities in Paraná as the highest with respect to suspected cases of dengue, i.e. 839 confirmed cases in the first two months of 2019 (Secretary of Health-Paraná, 2019). The Dengue Climatic Alert Service of the Climatology Laboratory (Laboclima, 2019) of the Federal University of Paraná (UFPR) provides information about the climatic conditions favourable for the development of Ae. aegypti. (Figure 1).

The Predestination Infestation Index (PII) is the relation expressed as a percentage of the number of properties positive with mosquito infestations and the number of real estate sites surveyed. This index classified the risk for epidemic development in Maringá as $3 \%$ in the first months of 2019 , which again is considered a high risk for dengue infestation. Household trash and small water collections constitute the main breeding grounds for the dengue vector mosquitoes in the city (Secretary of Health-Paraná, 2019).

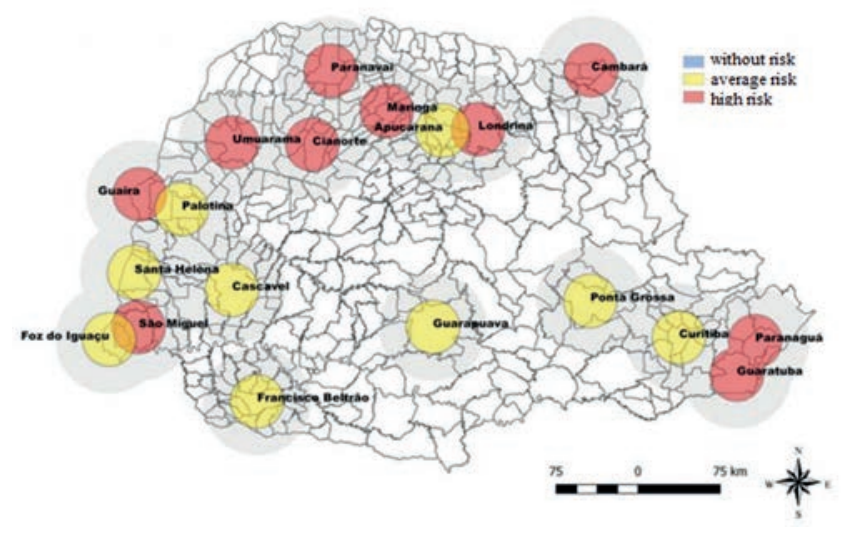

Figure 1. Climatic risk with respect to development of Ae. aegypti breeding sites by meteorological stations in Paraná 2019. Source: Climatology Laboratory of the Federal University of Paraná. 


\section{General approach}

Due to the conditions mentioned above, Maringá was felt to be ideal for testing of UAV technology as an aid in the identification Ae. aegypti breeding sites. This paper does not participate in an investigation of the actual use of AUVs for this specific application, but deals with the systematic evaluation of all the elements needed as a way to find the best UAV to fit this specification. The methodological procedure was done in four steps as schematically presented in Figure 2: i) definition of alternatives and criteria; ii) evaluation of criteria and sub-criteria; followed by iii) examination of the alternatives; and finally, iv) sensibility analysis.

\section{Definitions}

A team, specialized in evaluating technologies for the collection and treatment of spatial data identified the most suitable UAVs based on technical data and geo-processing capability to recognize mosquito breeding sites in urban areas. The alternatives included three different mini class models (A1, A2 and A3) selected from a collection of UAVs usually used for the aerial mapping of urban environments. Their commercial names are not disclosed as we focus on the decision process and not on a specific UAV.

Two technical specialists (D-1, D-2) were asked to jointly create the selection criteria (Table 1) and a set of pair-wise comparisons (Table 2) for the 9-degree scale introduced by Saaty (1980) to determine the weight of each criterion in the model. This step is important because to reach a useful decision, the UAVs must be analyzed according to a particular set of criteria applied in a standardized way based on the consistency ratio (CR) represented by the following formula:

$$
C R=\frac{\lambda-n}{(n-1) * R I}
$$

where $\lambda$ represents the maximum eigenvalue; $n$ the order of the comparison matrix; and $R I$ an index of random consistency defined by Saaty (1994) that depends on the number of criteria $(n)$ evalu- ated. The evaluations were considered coherent if they do not exceed the limit of 0,1 (Saaty, 1980). After certifying the judgment consistency, using a comparison matrix between the criteria, the geometric mean was conducted to obtain the weight vectors ${ }_{\mathrm{ij}}\left(w_{l}\right.$, $w j, w_{m}$ ) through calculating the eigenvalue of Matrix A. By finding the eigenvector $w$ of the matrix A, i.e., where is matrix's A maximum eigenvalue, the criteria priority can be estimated. Hence, once the vector $W$ is normalized, it becomes the priority vector that represents the weight of each criterion in the problem.

The six criteria in Table 1 represent the technical UAV specifications that have to be taken into account. The sensor was not used as a criterion because all the UAVs analyzed were equipped with the Advanced Photo System type-C (APS-C) sensors. However, all other criteria and sub-criteria proposed were used by the two experts to evaluate the performance of the three UVAs under study. Each criterion was subdivided into sub-criteria according to Table

\section{Table 1. Selection criteria}

Technical specification Performance specification

\begin{tabular}{|c|c|c|c|}
\hline & Weight & $\begin{array}{l}\text { C11 } \\
\text { C12 }\end{array}$ & $\begin{array}{l}\text { Maximum takeoff weight }(\mathrm{Kg}) \\
\text { Maximum payload weight }(\mathrm{Kg})\end{array}$ \\
\hline $\mathrm{C} 2$ & Dimension & $\mathrm{C} 21$ & Wingspan (m) \\
\hline C3 & Technique & $\begin{array}{l}\text { C31 } \\
\text { C32 }\end{array}$ & $\begin{array}{l}\text { Takeoff } \\
\text { Landing }\end{array}$ \\
\hline $\mathrm{C} 4$ & Performance & $\begin{array}{l}\text { C41 } \\
\text { C42 } \\
\text { C43 } \\
\text { C44 }\end{array}$ & $\begin{array}{l}\text { Maximum range }\left(\min ^{\mathrm{a}}\right) \\
\text { Maximum mapped area }\left(\mathrm{ha}^{\mathrm{b}}\right) \\
\text { Wind resistance }\left(\mathrm{Ktas}^{\mathrm{c}}\right) \\
\text { Maximum altitude }\left(\mathrm{ft}^{\mathrm{d}}\right)\end{array}$ \\
\hline $\mathrm{C} 5$ & Speed & $\begin{array}{l}\text { C51 } \\
\text { C52 } \\
\text { C53 }\end{array}$ & $\begin{array}{l}\text { Cruise speed (Ktas) } \\
\text { Stall speed (Ktas) } \\
\text { Maximum level speed (Ktas) }\end{array}$ \\
\hline $\mathrm{C} 6$ & Investment & $\begin{array}{l}\mathrm{C} 61 \\
\mathrm{C} 62\end{array}$ & $\begin{array}{l}\text { Initial investment (USD/year) } \\
\text { Maintenance cost (USD/year) }\end{array}$ \\
\hline
\end{tabular}

${ }^{\mathrm{a}}$ minutes; ${ }^{\text {bhectares }}\left(1 \mathrm{ha}=10,000 \mathrm{~m}^{2}\right)$; ${ }^{\text {KKtas }}=$ true airspeed measured in knots (nautical miles per hour, i.e. $1.852 \mathrm{~km} / \mathrm{h}) ;{ }^{\mathrm{d}}$ foot $(=0.3048 \mathrm{~m})$.
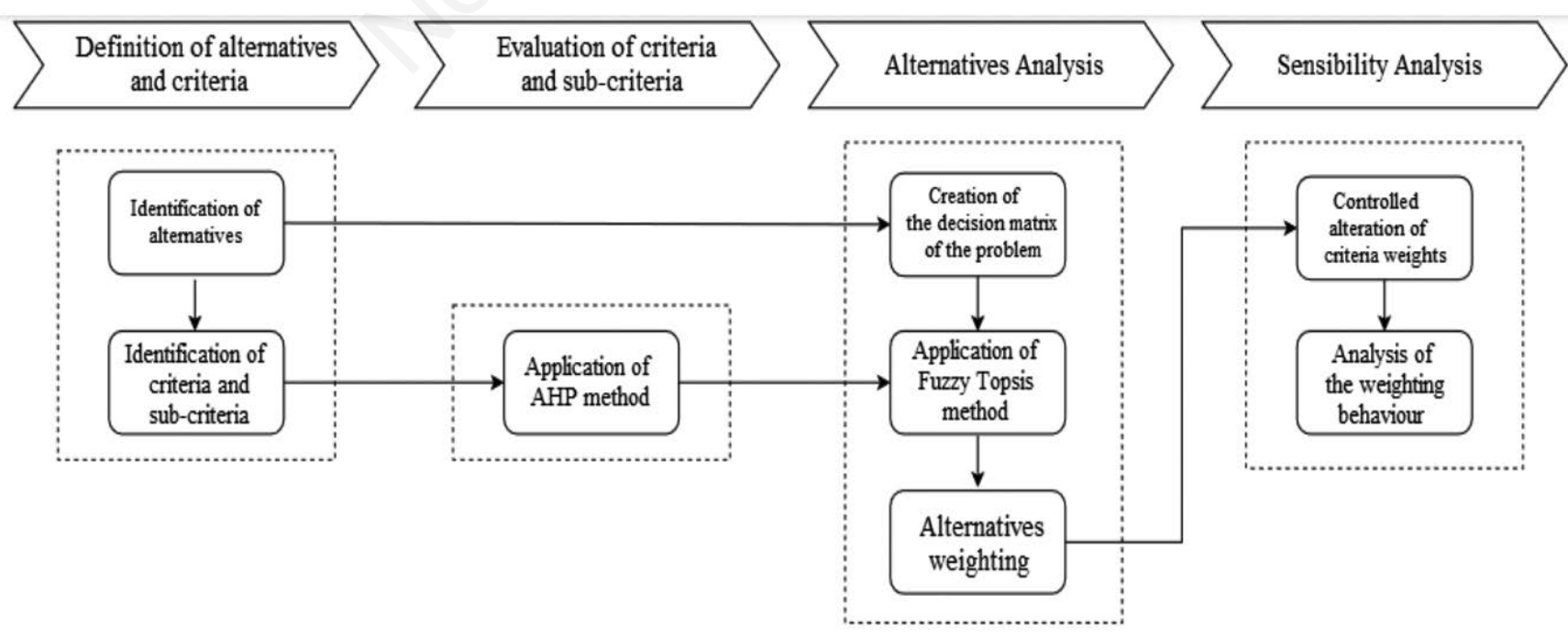

Figure 2. Methodological steps for decision-making. 
1 with the CR used to verify whether the technical eviw is complicit with the specific comparisons of each criterion. In other words, if criterion $\mathrm{C} 1$ is more preferable than $\mathrm{C} 2$, and $\mathrm{C} 2$ more preferable than $\mathrm{C} 3$, it would be inconsistent to say that $\mathrm{C} 3$ is more preferable than $\mathrm{C} 1$. When such inconsistencies are identified, the specialists must be consulted again to check that the responses attributed to each pair of evaluated criteria. The characterization of the criteria is described in Figure 3.

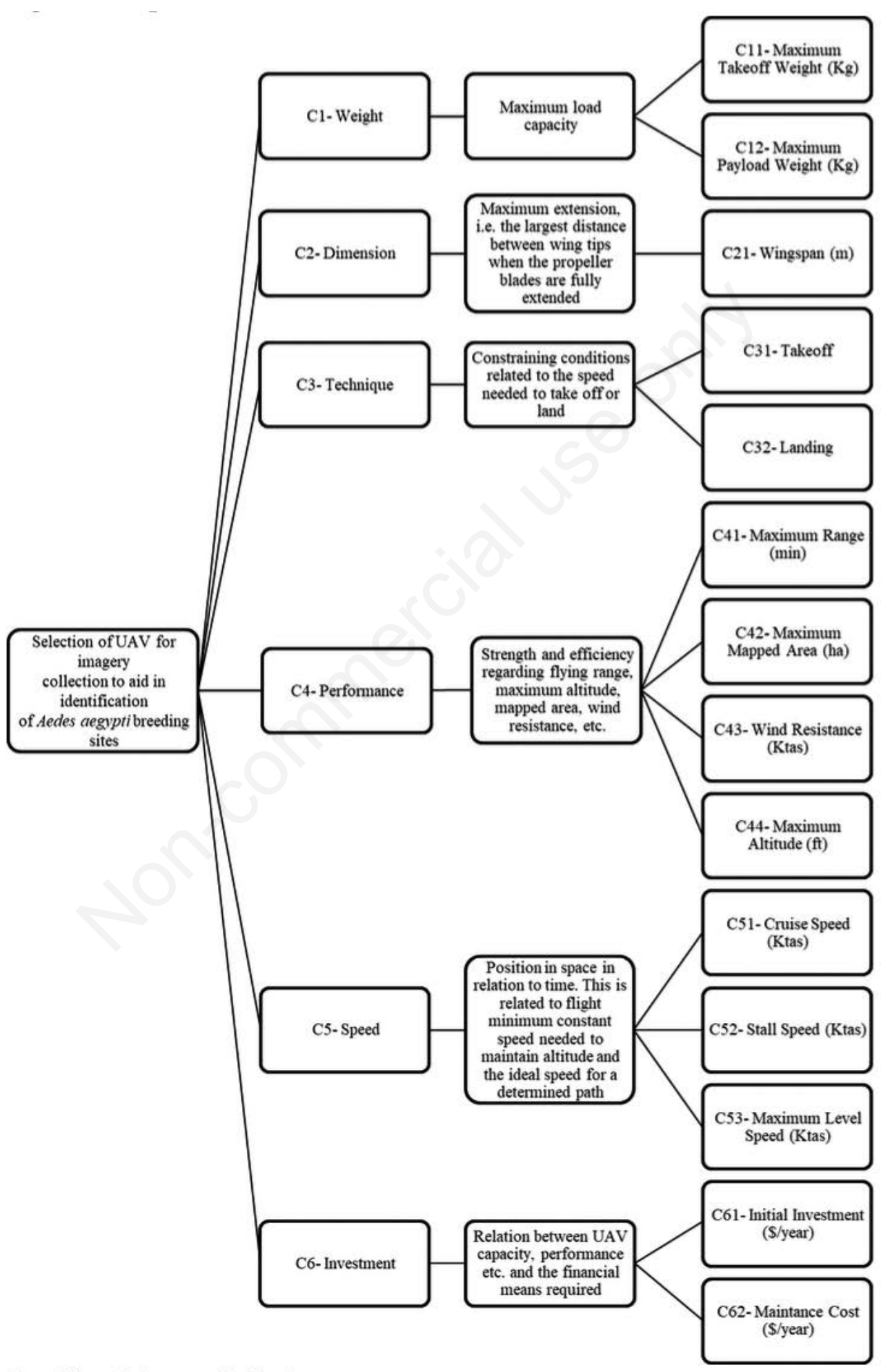

Figure 3. Requirements and criteria to be considered. For abbreviation see Table 1. 


\section{Evaluation}

After characterizing the criteria shown in Table 1, the next step was to use Table 2 determining the weights which allows identification of the level of performance within the analytical context. The pair-wise comparison was carried out by employing a judgment scale that returned the significance based on elective assessment of the weight of each measure. According to the AHP method, the decision-maker would compare each match based on comparison employing Saaty's 9-degree scale that ranges choices from 'equal importance' to 'vital importance'.

For example, when the outcome of the pair-wise comparison of $\mathrm{C} 1$ and $\mathrm{C} 2$, is that the former is more important than the latter, then the outcome for $\mathrm{C} 1$ will give it number 9 . However, if the decision would be the opposite, then the number has to be given as $1 / 9=0.11$. In this way, the pair-wise comparison information will generate a matrix filled out with the numerical judgments and its elements that satisfy the reciprocal property (Table 3 ).

\section{Analysis of alternatives}

The FST handles the uncertainty presented in the evaluated elements. Some decision problems face one or more subjective criteria that needs to be considered. To avoid the subjectivity of human judgment, we implemented FST, in which the subject criteria are expressed by linguistic variables related to fuzzy numbers. The fuzzy numbers might be represented in several distinct ways (Klir and Yuan, 1995). Here, we used the so-called trapezoidal fuzzy number, represented by $\widetilde{N}=(\mathrm{N} 1, \mathrm{~N} 2, \mathrm{~N} 3, \mathrm{~N} 4)$ carrying out the analysis as done by Xiao et al. (2012). In this description, the height of the trapezium that represents the membership function in terms of an ordered parameter is the largest membership grade in the set. By definition, the fuzzy subset in Universe X must be both

Table 2. Table for pair-wise comparison Linguistic term.

\begin{tabular}{ll} 
Linguistic term & Number \\
Equal importance & 1 \\
Between equal and moderate importance & 2 \\
\hline Moderately important & 3 \\
Between moderate and high importance & 4 \\
\hline Highly important & 5 \\
Between high and extreme importance & 6 \\
\hline Extremely important & 7 \\
Between extreme and vital importance & 8 \\
\hline Vital for the project & 9 \\
\hline
\end{tabular}

Table 3. Numerical judgments

\begin{tabular}{lccccccc} 
Criterion & C1 & C2 & C3 & C4 & C5 & C6 & V. Prior \\
C1 & - & 0,33 & 7 & 7 & 7 & 3 & 0,29570 \\
C2 & 3 & - & 7 & 8,00 & 8 & 3 & 0,44440 \\
\hline C3 & 0,14 & 0,14 & - & 5 & 2 & 1 & 0,08688 \\
C4 & 0,14 & 0,125 & 0,2 & - & 0,333 & 1 & 0,03762 \\
\hline C5 & 0,14 & 0,125 & 0,5 & 3 & - & 1 & 0,05885 \\
C6 & 0,33 & 0,33 & 1 & 1 & 1 & - & 0,07655 \\
\hline
\end{tabular}

normal and convex (Dubois, 1980). In other words, the fuzzy trapezoidal number consists of converting the qualitative parameter into quantitative numbers that can be represented by the shape as a trapezium composed of these four numbers. The ordered parameter here define the trapezoidal fuzzy numbers (PTFN) as a1, a2, a3, a4 (Figure 4). In fact, fuzzy numbers can be divided into three categories: positive fuzzy numbers, zero fuzzy numbers and negative fuzzy numbers. Usually, the negative fuzzy numbers originate from multiplication, division or subtraction in the formulas used, which is not the case in most MCDM methods, including fuzzy TOPSIS, where only positive fuzzy numbers are used (Terano et al., 2014).

Linguistic evaluation allows judgments regarding alternatives and criteria (Sousa et al. 2006; Chaves et al. 2017). As shown in Table 4 , those variables can be represented by trapezoidal fuzzy numbers. To solve the fuzzy problem, the decision-maker needs, first of all, to rate the alternatives with reference to the qualitative criteria, based on the linguist variables. As an example, the linguistic variable "Poor $(\mathrm{P})$ " can be defined as the mathematical figures $(1,2,2,3)$ using Table 4 as a reference (Dubois, 1980).

With the construction of the decision-diffused matrix bundled with the weight criteria $W_{i j}$, the hybrid combination of Fuzzy TOPSIS and the rating of alternatives related to the decision-maker criteria $\tilde{x} i j$ can be initialized. When solving a problem using decisionmaking methods, it is recommended to use fuzzy logic for qualitative criteria. For example, when buying a car, you may want to evaluate the criteria of beauty and comfort. However, what is beautiful and comfortable for one person can be totally different for another, so you might wish to use diffuse parameters allowing you to reach an average evaluation. This can be done by using the fuzzy

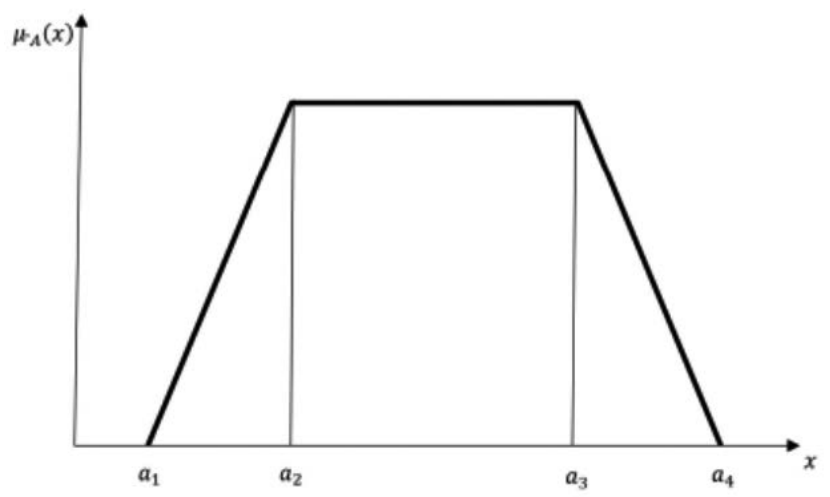

Figure 4. The trapezoidal fuzzy number

Table 4. Translation of linguistic variables into trapezoidal numbers.

\begin{tabular}{lrrrrr} 
Linguistic variable & Code & al & a2 & a3 & a4 \\
Very Poor & VP & 0 & 0 & 1 & 2 \\
Poor & P & 1 & 2 & 2 & 3 \\
\hline Medium poor & MP & 2 & 3 & 4 & 5 \\
Fair & F & 4 & 5 & 5 & 6 \\
\hline Medium good & MG & 5 & 6 & 7 & 8 \\
Good & G & 7 & 8 & 8 & 9 \\
\hline Very good & VG & 8 & 9 & 10 & 10 \\
\hline
\end{tabular}


trapezoidal number. After the development of a decision-diffused matrix, the same is normalized where $\tilde{r} i j$ for maximization criteria and minimization criteria can be calculated by equations 2 and 3 :

$\tilde{r}_{i j}=\left(\frac{a_{i j}}{d_{j}^{*}}, \frac{b_{i j}}{d_{j}^{*}}, \frac{c_{i j}}{d_{j}^{*}}, \frac{d_{i j}}{d_{j}^{*}}\right), j \in B$,

$$
\tilde{r}_{i j}=\left(\frac{a_{j}^{-}}{a_{i j}}, \frac{a_{j}^{-}}{c_{i j}}, \frac{a_{j}^{-}}{b_{i j}}, \frac{a_{j}^{-}}{a_{i j}}\right), j \in C,
$$

where the normalized weighted matrix $\widetilde{V}$ appears as the product of the multiplication of the criteria weights $\widetilde{w}$ with the fuzzy decision-normalized $\widetilde{r} i j$ as stated in equation 4 :

$$
\tilde{v}_{i j}=\tilde{r}_{i j}(\cdot) \widetilde{w}_{j}
$$

Then the fuzzy positive ideal solution (FPIS=A*) and the fuzzy negative ideal solution (FNIS=A-) can be calculated using equations 5 and 6 :

$$
A^{*}=\left(\tilde{v}_{1}^{*}, \tilde{v}_{2}^{*}, \ldots, \tilde{v}_{n}^{*}\right)
$$

$$
A^{-}=\left(\tilde{v}_{1}^{-}, \tilde{v}_{2}^{-}, \ldots, \tilde{v}_{n}^{-}\right)
$$

Eq. 6

It is also necessary to calculate the distances between each alternative (A1, A2, A3) to the fuzzy positive and negative ideal solutions $\left(\mathrm{A}^{*}\right.$ and $\left.\mathrm{A}^{-}\right)$. This distance is called $\mathrm{d}_{i}^{+}$(distance from the positive ideal solution) and $\mathrm{d}_{\mathrm{i}}^{-}$(distance from the negative ideal solution) and can be calculated by equations 7 and 8 :

$$
d_{i}^{*}=\sum_{j=1}^{n} d_{v}\left(\tilde{v}_{i j}, \tilde{v}_{j}^{*}\right), i=1,2, \ldots, m,
$$

$$
d_{i}^{-}=\sum_{j=1}^{n} d_{v}\left(\tilde{v}_{i j}, \tilde{v}_{j}^{-}\right), i=1,2, \ldots, m,
$$

Finally, the proximity coefficient $\left(C C_{i}\right)$, that estimates how far away the alternative is from the ideal (FPIS) and anti-ideal solution (FNIS), can be calculated by the use of equation 9 establishing the outcome of the distances between $\mathrm{A}^{+}$and $\mathrm{A}^{\text {- }}$.

$$
C C_{i}=\frac{d_{i}^{-}}{d_{i}^{*}+d_{i}^{-}}, i=1,2, \ldots, m
$$

The proximity coefficient $C C_{i}$ classifies the alternatives in an order allowing us to pinpoint the alternative whose performance places it closest to the FPIS and furthest from the FNIS. Calculation of the $\mathrm{CC} i$ for all alternatives, establishes a rank based on the preference quality of the alternatives.

\section{Sensitivity analysis}

A sensitivity analysis was conducted with the aim of observing the alternative behaviour in relation to the criteria of weight variables. This step is needed to analyze the alternatives with regard to the criteria to illustrate those that disturb the generated ranking (Wolters, 1955; Zola et al., 2020). Our purpose with the analysis was to identify the most sensible criteria and sub criteria. To that end, we defined the values $0.0 ; 0.25 ; 0.5 ; 0.75 ; 1.0$ as intervals in the weight criteria to evaluate the impact at the UAV selection.

\section{Results}

The way to find the UAV model of choice for the identification of Ae. aegypti breeding sites for the city of Maringá is presented below. The hierarchical structure of the problem studied here is presented in Figure 5.

In MCDM there are two types of criteria. The critera that strengthens the preferred choice are called maximizing (or benefitting) criteria, while criteria that downgrade the preferred choice are called minimizing (or cost) criteria. Here, C21, C31, C32, C41, $\mathrm{C} 42, \mathrm{C} 43, \mathrm{C} 44, \mathrm{C} 51, \mathrm{C} 52, \mathrm{C} 53$ were classified as maximizing criteria, and C21, C61 and C62 minimizing ones. By means of the Fuzzy TOPSIS method the calculation to identify the best alternative starts from this knowledge base. Table 5 shows the decision matrix which contains information about each alternative in relation to each criterion evaluated. The two experts (D-1 and D-2) were invited to evaluate the $\mathrm{C} 31$ and $\mathrm{C} 32$ criteria by using the lin-

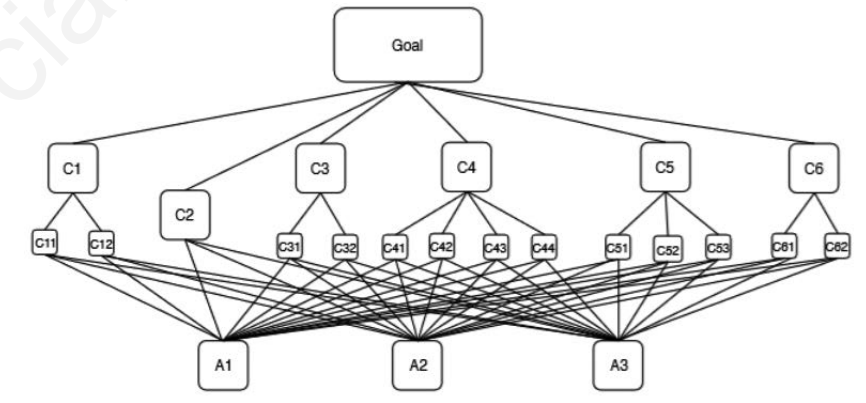

Figure 5. Hierarchical structure of the problem.

Table 5. Decision matrix.

\begin{tabular}{lcccccc} 
Criteria & & & Weight & UAV-A1 & UAV-A2 & UAV-A3 \\
C1 & C11 & + & 0.13 & 7.6 & 3.3 & 25 \\
& C12 & + & 0.06 & 0.9 & 0.35 & 11.5 \\
C2 & C21 & - & 0.34 & 2.13 & 1.2 & 1.2 \\
\hline C3 & C31 & + & 0.04 & Catapult & Catapult & Hand launch \\
& C32 & + & 0.08 & Parachute & Parachute & Parachute \\
C4 & C41 & + & 0.02 & 60 & 87 & 600 \\
& C42 & + & 0.01 & 1100 & 1100 & 49000 \\
& C43 & + & 0.02 & 45 & 45 & 45 \\
& C44 & + & 0.02 & 3000 & 3000 & 3000 \\
\hline C5 & C51 & + & 0.03 & 57.6 & 57.6 & 108 \\
& C52 & + & 0.03 & 43 & 43 & 58 \\
& C53 & + & 0.06 & 72 & 72 & 122 \\
C6 & C61 & - & 0.05 & 180000 & 75000 & 200000 \\
& C62 & - & 0.10 & 3812 & 3812 & 3812 \\
\hline
\end{tabular}


guistic variables shown in Table 6, which in turn are based on Table 4 .

The decision matrix was 'fuzzified', that is, the linguistic variables were translated into trapezoidal fuzzy numbers. Now, we undertook an evaluation of the importance of the criteria and subcriteria. The two technical experts were now invited to compare the technical specifications and their performance in order to decide the importance of the weights which was done by pair-wise comparison using the Saaty scale (1980). The weights are presented in Table 7.

In the next stage, the matrix normalization and the fuzzification decision were realized by means of equations 2 and 3. Owing to this, the normalized decision was considered as a matrix built using equation 4 . Later the FPIS and FNIS, can be calculated by equations 5 and 6 (Table 8). Following this, it is necessary to calculate the distances between the alternatives of FPIS and FNIS for each aspect according to equations 7 and 8 , which determine the distance between the alternatives $\mathrm{d}^{*}$ and $\mathrm{d}$-, which simplifies the coefficient calculation of proximity $\left(C C_{i}\right)$ of each alternative. This was done by equation 9 as Table 9 shows. The result of this assessment, based on proximity coefficients ranking A1, A2 and A3 as $\mathrm{A} 1>\mathrm{A} 3>\mathrm{A} 2$ due to the weights assigned. However, it should be emphasized that if modifications with regard to the weights and/or the matrix composition of the decision, the ranking may be changed.

\section{Sensitivity Analysis}

For the analysis of the impact of the criteria concerning UAV selection, a sensitivity analysis was realized, to evaluate how sensitive the methodology is for the different scenarios. Therefore, six scenarios were created, one of each criterion, where the weight of the criterion was variated being $0,0.25,0.5,0.75$ and 1 . All the other weights were recalculated maintaining the proportion generated by Table 6 . The combinations of standards values enabled us

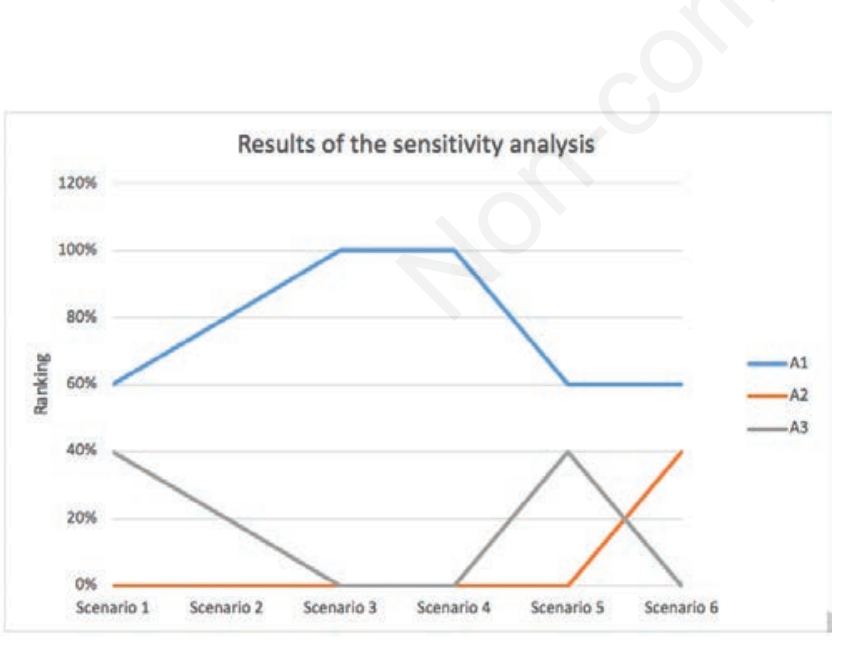

Figure 6. Sensitivity analysis. The scenarios were created to vary the weight of the criteria in values of 0.25 in the applied sensitivity analysis to identify whether there is a relevant change in the final UAV ranking in case the weight of the criteria changes significantly. The criterion component associates a variety of uncertainties with the results obtained in the decision-making carried out by multicriterial evaluation. These uncertainties can be identified and evaluated by a sensitivity analysis that determines the robustness of the solutions obtained in the decision-making process.
Table 6. Linguistic variables of criteria C31 and C32.

\begin{tabular}{llcc} 
Criterion & UAV alternative & \multicolumn{2}{c}{ Linguistic code } \\
& & D-1 & D-2 \\
C31 & A1 & F & MP \\
& A2 & F & MP \\
& A3 & VG & VG \\
C32 & Al & MG & G \\
& A2 & MG & G \\
& A3 & MG & G \\
\hline
\end{tabular}

D-1 and D2 represents experts; Other abbreviations as of Table 3.

Table 7. Criterion weights.

\begin{tabular}{lll} 
Criterion & & Weight \\
$\mathrm{C} 1$ & $\mathrm{C} 11$ & 0.13 \\
& $\mathrm{C} 12$ & 0.06 \\
$\mathrm{C} 2$ & $\mathrm{C} 21$ & 0.34 \\
\hline $\mathrm{C} 3$ & $\mathrm{C} 31$ & 0.04 \\
& $\mathrm{C} 32$ & 0.08 \\
$\mathrm{C} 4$ & $\mathrm{C} 41$ & 0.02 \\
& $\mathrm{C} 42$ & 0.01 \\
& $\mathrm{C} 43$ & 0.02 \\
& $\mathrm{C} 44$ & 0.02 \\
\hline $\mathrm{C} 5$ & $\mathrm{C} 51$ & 0.03 \\
& $\mathrm{C} 52$ & 0.03 \\
& $\mathrm{C} 53$ & 0.06 \\
$\mathrm{C} 6$ & $\mathrm{C} 61$ & 0.05 \\
& $\mathrm{C} 62$ & 0.10 \\
\hline
\end{tabular}

Table 8. Matrix of ideal positive solution and ideal negative solutions.

\begin{tabular}{lccc} 
Criterion & & $\mathrm{A}^{*}$ & $\mathrm{~A}-$ \\
$\mathrm{C} 1$ & C11 & $0.13 ; 0.13 ; 0.13 ; 0.13$ & $0.02 ; 0.02 ; 0.02 ; 0.02$ \\
& C12 & $0.06 ; 0.06 ; 0.06 ; 0.06$ & $0.0 ; 0.0 ; 0.0 ; 0.0$ \\
C2 & C21 & $0.34 ; 0.34 ; 0.34 ; 0.34$ & $0.19 ; 0.19 ; 0.19 ; 0.19$ \\
\hline C3 & C31 & $0.04 ; 0.04 ; 0.04 ; 0.04$ & $0.012 ; 0.016 ; 0.018 ; 0.022$ \\
& C32 & $0.09 ; 0.09 ; 0.09 ; 0.09$ & $0.061 ; 0.071 ; 0.076 ; 0.086$ \\
C4 & C41 & $0.01 ; 0.01 ; 0.01 ; 0.01$ & $0.01 ; 0.01 ; 0.01 ; 0.01$ \\
& C42 & $0.01 ; 0.01 ; 0.01 ; 0.01$ & $0.0 ; 0.0 ; 0.0 ; 0.0$ \\
& C43 & $0.56 ; 0.56 ; 0.56 ; 0.56$ & $0.01 ; 0.01 ; 0.01 ; 0.01$ \\
& C44 & $0.02 ; 0.02 ; 0.02 ; 0.02$ & $0.02 ; 0.02 ; 0.02 ; 0.02$ \\
\hline C5 & C51 & $0.03 ; 0.03 ; 0.03 ; 0.03$ & $0.01 ; 0.01 ; 0.01 ; 0.01$ \\
& C52 & $0.03 ; 0.03 ; 0.03 ; 0.03$ & $0.03 ; 0.03 ; 0.03 ; 0.03$ \\
& C53 & $0.06 ; 0.06 ; 0.06 ; 0.06$ & $0.04 ; 0.04 ; 0.04 ; 0.04$ \\
C6 & C61 & $(0.05 ; 0.05 ; 0.05 ; 0.05)$ & $(0.02 ; 0.02 ; 0.02 ; 0.02)$ \\
& C62 & $(0.10 ; 0.10 ; 0.10 ; 0.10)$ & $(0.10 ; 0.10 ; 0.10 ; 0.10)$ \\
\hline
\end{tabular}

$\mathrm{A}^{*}=$ ideal solution (EPIS); $\mathrm{A}$-=least ideal solution (FNIS).

Table 9. CCi results.

\begin{tabular}{llll} 
UAV & $d^{*}$ & $d-$ & $C_{i}$ \\
A1 & 0.74 & 0.90 & 0.55 \\
A2 & 1.05 & 0.72 & 0.41 \\
\hline A3 & 0.86 & 0.91 & 0.51 \\
\hline
\end{tabular}

$\mathrm{d}^{*}=$ distance to the ideal solution (EPIS); $\mathrm{d}-=$ distance to the least ideal solution (FNIS). 
to calculate the proximity coefficient ( $C C i$ ) of the Fuzzy TOPSIS method for each alternative in each scenario. The sensitivity analysis allowed testing the performance of alternatives in different criteria composition studied, to check how sensitive the methodology is for each criterion. In figure 6, we see that alternative A1 has an utmost classification in all scenarios, so the order $\mathrm{A} 1>\mathrm{A} 3>\mathrm{A} 2$ is observed in four out of the six scenarios (Figure 6). As a result, for this scenarios composition, the performance of the alternatives kept themselves at the current $66 \%$ of the analysis, showing the ranking method Fuzzy TOPSIS is relatively insensitive to variation of weights of criteria.

\section{Discussion}

The search presented here proposes a model to identify the most appropriated UAV to help identify breeding foci of the main arbovirus vector $A e$. aegypti, whose proliferation is considered a major problem to public health, particularly as the vector has the capacity of adaptation to new environments. To find the breeding sites we used MCDM for deciding which UAV to choose, investigating alternatives and criteria with respect to weight, dimension, technique, performance, velocity and investment. The AHP approach together with Fuzzy TOPSIS allowed direct analysis and support the UAV evaluation rating which equipment presents the best performance based on the used criteria in the process of decision-making.

The sensitivity analysis allowed testing of the performance of evaluated alternatives in different scenarios, and the application of such analysis showed Fuzzy TOPSIS to be stable in rating the scale of alternatives, as the variation in rating scale was low. The results of this study should be useful with respect to guidance of public agents to which options to choose the equipment which allow a more efficient work of public health agents with difficult accessibility in the urban area, being the utilization of UAV an inexpensive and productive technology, compared to traditional methods for the acquisition of geospatial information.

To finish, the utilization of mathematical methods to make decision showed efficient for the problem solution of this search, as the process of evaluation of UAV to problems related with vector Ae. aegypti can become more robust and trustier. For that, it can be affirmed that all defined criteria are important and should be considered; however, it will depend on the characteristics to be analysed in problems of decision.

Considering the Development of Sustainable Objectives (DSO), whose actions intend to change the world, our search has an important contribution since it shows that it is possible to reduce problems of public health and contribute to achieving the goal of becoming an inclusive, safe, resilient, and sustainable city with low-cost actions.

\section{References}

Amarasinghe A, Suduwella C, Niroshan L, Elvitigala C, De Zoysa K, Keppetiyagama C, 2017. Suppressing dengue via a drone system. In Seventeenth International Conference on Advances in Information and communications technology (ICT) for Emerging Regions (ICTer). Institute of Electrical and Electronics Engineers (IEEE) pp. 1-7.

Amenyo JT, Phelps D, Oladipo O, Sewovoe-Ekuoe F, Jadoonanan
S, Jadoonanan S et al., 2014. MedizDroids Project: Ultra-low cost, low-altitude, affordable and sustainable UAV multicopter drones for mosquito vector control in malaria disease management. In Institute of Electrical and Electronics Engineers (IEEE) Global Humanitarian Technology Conference (GHTC 2014). pp. 590-596. IEEE. 10.1109/GHTC.2014.6970343.

Bhatt S, Gething PW, Brady OJ, Messina JP, Farlow AW, Moyes CL, Drake JM, et al., 2013. The global distribution and burden of dengue. Nature 496: 504-7. doi: 10.1038/nature12060.

Brown JE, Evans BR, Zheng W, Obas V, Barrera $\square$ Martinez L, Egizi A et al., 2014. Human impacts have shaped historical and recent evolution in Aedes aegypti, the dengue and yellow fever mosquito. Evolution 68:514-25. doi: 10.1111/evo.12281.

Carvalho S, Magalhães MDAFM, Medronho RDA, 2017. [Análise da distribuição espacial de casos da dengue no município do Rio de Janeiro, 2011 e 2012.] Rev Saúde Pública 51:79. doi: 10.11606/s1518-8787.2017051006239. [Article in Portuguese].

Chaves, L. E., Nascimento, L. F. C., \& Rizol, P. M. S. R, 2017. [Modelo fuzzy para estimar o número de internações por asma e pneumonia sob os efeitos da poluição do ar.] Rev Saúde Pública 51:1-8. doi: 10.1590/S1518-8787.2017051006501 1. [Article in Portuguese].

Chen CT, 2000. Extensions of the TOPSIS for group decisionmaking under fuzzy environment. Fuzzy Sets and Systems 114:1-9. doi: 10.1016/S0165-0114(97) 00377 -1.

Chiroli DMG, Montilha MM, Samed MMA, 2017. Feasibility analysis of UAV in dengue control. Independent Journal of Management \& Production 8:319-34. doi: 10.14807/ijmp.v8i2.539.

Donalisio MR, Freitas ARR, Zuben APBV, 2017. Arboviruses emerging in Brazil: challenges for clinic and implications for public health. Revista de Saúde Pública 51:30. doi.org/10.1590/s1518-8787.2017051006889.

Dubois DJ, 1980. Fuzzy sets and systems: theory and applications (Vol. 144). Academic Press.

Espinosa MO, Polop F, Rotela CH, Abril M, Scavuzzo CM, 2016. Spatial pattern evolution of Aedes aegypti breeding sites in an Argentinean city without a dengue vector control programme. Geospatial Health 11:471. doi :10.4081/gh.2016.471.

Ferreira AC, Chiaravalloti F, Mondini A, 2018. Dengue em Araraquara, SP: epidemiologia, clima e infestação por Aedes aegypti. Rev Saúde Pública 52. doi: 10.11606/S15188787.2018052000414.

Gloria $\square$ Soria A, Ayala D, Bheecarry A, Calderon $\square$ Arguedas O, Chadee DD, Chiappero M, et al., 2016. Global genetic diversity of Aedes aegypti. Molecular Ecology 25:5377-95. doi: 10.1111/mec.13866.

Hay SL, George DB, Moyes CL, Brownstein JS, 2013. Big data opportunities for global infectious disease surveillance. PLoS Medicine 10:e1001413. doi: 10.1371/journal.pmed.1001413.

Hwang CL, Lai YJ, Liu TY, 1993. A new approach for multiple objective decision making. Comput Oper Res 20:889-99. doi:10.1016/0305-0548(93)90109-v.

Hwang CL, Yoon K, 1981. In Multiple Attribute Decision Making: Methods and Applications. New York: Springer-Verlag.

IBGE, 2010. [IBGE - Instituto Brasileiro de Geografia Estatística (2010). Panorama.] Available from: https://cidades.ibge.gov.br/brasil/pr/maringa/panorama. Accessed March 2019. [Website in Portuguese].

International Atomic Energy Agency (IAEA), 2018. IAEA 
Conducts Successful Test of Unmanned Aerial Vehicles in Fight Against Disease-Transmitting Mosquitos. Available from: https: www.iaea.org/newscenter/pressreleases/iaea-conducts-successful-test-of-drones-in-fight-against-disease-transmitting-mosquitos \#: : text=The $\% 20$ International $\% 20$ Atomic $\% 20$ Energy $\% 20$ Agency,spreads $\% 20$ Zika\%20and $\% 20$ other $\% 20$ diseases.\&text $=$ As $\% 20$ these $\% 20$ do $\% 20$ not $\% 20$ produce, insect $\% 20$ population $\% 20$ declines $\% 20$ over $\% 20$ time. Accessed: May 2018.

Khormi HM, Kumar L, 2012. Assessing the risk for dengue fever based on socioeconomic and environmental variables in a geographical information system environment. Geospat Health 6:171-6. doi: 10.4081/gh.2012.135.

Khormi HM, Kumar L, 2014. Climate change and the potential global distribution of Aedes aegypti: spatial modelling using geographical information system and CLIMEX. Geospat Health 8:405-15. doi: 10.4081/gh.2014.29

Klir G, Yuan B, 1995. Fuzzy sets and fuzzy logic (Vol. 4). New Jersey, USA. Prentice Hall.

Laboclima/UFPR, 2019. Climatic risk to development of breeding ground by Meteorological Stations. Available from: http://www.terra.ufpr.br/portal/laboclima/sacdengue/ Accessed: Mach 2019.

Liu B, Gao X, Ma J, Jiao Z, Xiao J, Hayat MA, Wang H, 2019. Modeling the present and future distribution of arbovirus vectors Aedes aegypti and Aedes albopictus under climate change scenarios in Mainland China. Science of The Total Environment 664:203-14. doi: 10.1016/j.scitotenv.2019.01.301.

Liu-Helmersson J, Rocklöv J, Sewe M, Brännström A, 2019. Climate change may enable Aedes aegypti infestation in major European cities by 2100. Environ Res 172:693-9. doi: 10.1016/j.envres.2019.02.026.

Machault V, Vignolles C, Borchi F, Vounatsou P, Pages F, Briolant $\mathrm{S}$ et al., 2011. The use of remotely sensed environmental data in the study of malaria. Geospat Health 5:151-68. doi: 10.4081/gh.2011.167.

Madariaga M, Ticona E, Resurrecion C, 2016. Chikungunya: bending over the Americas and the rest of the world. Braz J Inf Dis 20:91-8. doi: 10.1016/j.bjid.2015.10.004.

Mahdi IM, Alreshaid K, 2005. Decision support system for selecting the proper project delivery method using analytical hierarchy process (AHP). Int J Proj Manage 564-72.

Maitra A, Cunha-Machado AS, de Souza Leandro A, da Costa FM,
Scarpassa VM, 2019. Exploring deeper genetic structures: Aedes aegypti in Brazil. Acta Tropica 195:68-77. doi: 10.1016/j.actatropica.2019.04.027

Saaty TL, 1980. The Analytic Network Process. 1 ed. McGraw Hill: New York, NY, USA.

Saaty TL, 1994. Fundamentals of Decision Making. RWS Publications, Pittsburgh, PA, USA.

Sarfraz MS, Tripathi NK, Faruque FS, Bajwa UI, Kitamoto A et al., 2014. Mapping urban and peri-urban breeding habitats of Aedes mosquitoes using a fuzzy analytical hierarchical process based on climatic and physical parameters. Geospat Health S685-97. doi: 10.4081/gh.2014.297.

Secretary of Health-Paraná, 2019. Boletim da dengue (2019). Available at http://www.dengue.pr.gov.br/modules/ conteudo/conteudo.php?conteudo=28. Accessed March 2019.

Sousa CAD, Duarte PS, Pereira JCR, 2006. [Lógica fuzzy e regressão logística na decisão para prática de cintilografia das paratiróides.] Rev Saúde Pública. 40:898-906. [Article in Portoguese].

Terano T, Asai K, Sugeno M, eds, 2014 Applied fuzzy systems. Academic Press, 2014.

Turner D, Lucieer A, de Jong S, 2015. Time series analysis of landslide dynamics using an unmanned aerial vehicle (UAV). Remote Sensing 7:1736-57. doi: 10.3390/rs70201736.

Tzeng GH, Huang JJ, 2011. Multiple attribute decision making: methods and applications. Chapman and Hall/CRC.

WHO, 2017. What is dengue and how is it treated? Available from: http://www.who.int/features/qa/54/en/. Accessed: May 2018.

WHO, 2020. Available from: https:/www.who.int/westernpacific/emergencies/surveillance/dengue

Wolters WTM, Mareschal B, 1955. Novel types of sensitivity analysis for additive MCDM methods. European J Oper Res 81:281-90. doi.org/10.1016/0377-2217(93)E0343-V.

Xiao Z, Xia S, Gong K, Li D, 2012. The trapezoidal fuzzy soft set and its application in MCDM. Applied Mathematical Modelling 36:5844-55. doi: 10.1016/j.apm.2012.01.036.

Yoon K, 1987. A reconciliation among discrete compromise situations. J Oper Res Soc 38:277-86. doi: 10.1057/jors.1987.44.

Zadeh LA, 1965. Fuzzy sets. Inf Control 8:338-53.

Zola FC, Colmenero JC, Aragão FV, Rodrigues T, Junior AB, 2020. Multicriterial model for selecting a charcoal kiln. Energy 190:116377. doi: org/10.1016/j.energy.2019.116377. 